\title{
Oxygen Plasma Modification of Poly(3-hydroxybutyrate-co- 3-hydroxyvalerate) Film Surfaces for Tissue Engineering Purposes
}

\author{
V. Hasirci, ${ }^{1}$ A. Tezcaner, ${ }^{1}$ N. Hasirci, ${ }^{2}$ Ş. Süzer ${ }^{3}$ \\ ${ }^{1}$ Middle East Technical University, Department of Biological Sciences, Biotechnology Research Unit, \\ 06531 Ankara, Turkey \\ ${ }^{2}$ Middle East Technical University, Chemistry Department, 06531 Ankara, Turkey \\ ${ }^{3}$ Bilkent University, Chemistry Department, 06533 Ankara, Turkey
}

Received 6 November 2000; accepted 2 April 2002

\begin{abstract}
Plasma glow-discharge application is known as a technique to coat or modify the surfaces of various materials. In this study, the influence of oxygen rf-plasma treatment on surface and bulk properties of a biological polyester, poly(3-hydroxybutyrate-co-3-hydroxyvalerate), were studied by determining water content and water contact angle, and by using X-ray photoelectron spectroscopy (XPS) and scanning electron microscopy (SEM). The plasmatreated films absorbed more water than the untreated film, and the absorbance increased with the total power applied. The water contact angles decreased and $\mathrm{O} / \mathrm{C}$ atomic ratio increased on treatment, indicating that the material became more hydrophilic due to increases in the oxygen-containing
\end{abstract}

functional groups on the surface of the polymer. A direct relation could be observed when the $\mathrm{O} / \mathrm{C}$ ratio was plotted against the total power applied (treatment duration $X$ treatment power). SEM revealed a visual record of surface modification, the extent of which increased with increased total power. It was thus possible to alter the surface chemistry and relevant properties of the polymer film using oxygen plasma as a tool. (C) 2002 Wiley Periodicals, Inc. J Appl Polym Sci 87: 1285-1289, 2003

Key words: plasma polymerization; hydrophilic polymers; biodegadable biomaterials

\section{INTRODUCTION}

Polyhydroxyalkanoates (PHAs) are polyesters of microbial origin. The chemical structure of PHAs is very similar to those of polylactides (PLAs), the highly popular synthetic biodegradable polymers used in biomedical applications, and copolymers of PLAs with glycolides, [i.e., poly(lactide-co-glycolide) (PLGA)]. PHAs, however, generally degrade at a much slower rate than PLAs and PLGA. ${ }^{1}$ Poly(3-hydroxybutyrate) (P3HB) is generally found as a copolymer containing hydroxyvalerate (HV) as the comonomer, which is called poly(hydroxybutyrate-co-hydroxyvalerate) (PHBV). The copolymers have varying HV ratios, and their mechanical (tensile and compressive strengths) and chemical (surface energy, hydrolysis rate) properties depend on the HV content. They are biodegradable and biocompatible, and are reported to induce new bone formation due to their piezoelectricity. The interest in PHA is increasing rapidly, and exciting new applications in the fields of drug delivery and tissue engineering are being reported..$^{2-5}$ The biomedical field has been using PLGAs for sometime to fulfill its

Correspondence to: V. Hasirci (vhasirci@metu.edu.tr).

Journal of Applied Polymer Science, Vol. 87, 1285-1289 (2003) (C) 2002 Wiley Periodicals, Inc. need for biodegradable materials. The biological origin of PHBV, however, makes it environmentally more acceptable, which is a major advantage over PLGA. In addition, it is possible to obtain very different copolymers of PHAs with exceptional properties by just changing the carbon source of the growth medium of the PHA-producing microorganisms.

PHAs are produced by a large number of microorganisms, including Alcaligenes latus, Alcaligenes eutrophus, and Pseudomonas oleovorans. ${ }^{6-8}$ Genes for PHBV growth were introduced to other biological systems that are normally nonproducers (like E. coli) ${ }^{9}$ and even into plants. ${ }^{10}$ As a result, this polyester family has great potential in the biomedical field, especially as biodegradable implant materials, drug release systems, and tissue engineering scaffolds. In all these applications, the surface properties of the polymer are of utmost importance because the surface is the region of contact with the biological system. For example, bovine aortic endothelial cell growth was linearly correlated with the oxygen content obtained by the oxygen plasma treatment of the polymeric matrix. ${ }^{11}$ As a result of this interaction, cell loading and attachment to a biomaterial in tissue engineering applications, and the biocompatibility and biodegradability of the polymeric matrices are influenced. ${ }^{12}$ In this study, PHBV8 (PHBV with $8 \% \mathrm{HV}$ ) was treated at varying levels 
TABLE I

Water Content (\%) of PHBV8 Polymer Films in Pristine and Oxygen Plasma-Treated State after Incubation in PBS at $37^{\circ} \mathrm{C}$ for Various Durations

\begin{tabular}{ccc}
\hline \multirow{2}{*}{$\begin{array}{c}\text { Power applied } \\
(\text { Watt } \times \text { min })\end{array}$} & \multicolumn{2}{c}{ Water content $(\%)$} \\
\cline { 2 - 3 } & 24 h Incubation & 72 h Incubation \\
\hline 0 & 0 & $8.2 \pm 1.1$ \\
$50 \times 10$ & $4.6 \pm 0.3$ & $11.4 \pm 0.0$ \\
$50 \times 20$ & $4.1 \pm 0.6$ & $19.2 \pm 4.9$ \\
$100 \times 10$ & $11.2 \pm 1.8$ & $29.2 \pm 5.9$ \\
$100 \times 20$ & $13.3 \pm 5.6$ & $60.2 \pm 11.0$ \\
\hline
\end{tabular}

with oxygen plasma, the modifications created on the surface of this material were studied by X-ray photoelectron spectroscopy (XPS), and the water content and water contact angle values were measured.

\section{MATERIALS AND METHODS}

\section{Plasma treatment of polymer films}

Poly(3-hydroxybutyrate-co-3-hydroxyvalerate) (PHBV) containing $8 \%$ hydroxyvalerate (molar) in its structure was purchased from Aldrich Chemical Company (Germany) and films (8-10 $\mu \mathrm{m}$ thickness) were prepared by solvent casting of $0.6 \%$ solutions in chloroform in Petri plates $(9 \mathrm{~cm}$ in diameter). The films, in their Petri plates, were placed in a plasma chamber (Advanced Plasma Systems, Inc., (St. Petersburg, FL), with a SEREN IPS R $30013.56 \mathrm{MHz}$ power supply) and subjected to oxygen plasma (pressure: 40 mTorr initial and 300 mTorr final; see Table I for conditions). The membranes were then removed and used in further tests, taking care to identify the treated sides.

\section{Water content determination}

Water content of the polymeric films was determined by gravimetry. A sample (5-10 mg) was weighed to the nearest $0.1 \mathrm{mg}$, immersed in physiological phosphate buffer (PBS; pH 7.4, $0.1 \mathrm{M}$ ), and stored at $37^{\circ}$ for 24 and $72 \mathrm{~h}$. At $24 \mathrm{~h}$, the sample was removed, superficial water was removed by gently blotting with a filter paper, and the sample was weighed and then re-introduced into the swelling medium. At $72 \mathrm{~h}$, this weighing procedure was repeated and then the film was dried in a vacuum oven at $50^{\circ} \mathrm{C}$ overnight and weighed again. The water content was calculated as:

$$
\begin{aligned}
& \left(W_{\text {weight of wet sample }}-W_{\text {weight of dry sample }}\right) \\
& \quad \div W_{\text {weight of dry sample }} \times 100
\end{aligned}
$$

\section{Water contact angle determination}

Advancing contact angle measurements were made with a sessile drop of deionized water on a Cam-Micro
(Tantec Inc., (Schaumberg, IL)) contact angle meter. The values reported are an average of at least five measurements.

\section{X-ray photoelectron spectroscopy (XPS)}

XPS measurements were performed on films prepared on glass slides using a Kratos ES300 spectrometer with $\mathrm{MgK} \alpha$ X-rays at $1253.6 \mathrm{eV}$. The films on the slides were directly inserted into the spectrometer, which had a base pressure $>10^{-8}$ Torr. Power was kept at $<100 \mathrm{Watt} / \mathrm{cm}^{2}$ to prevent any radiation damage.

\section{Scanning electron microscopy (SEM)}

Scanning electron micrographs of PHBV8 films, before and after plasma treatment, were obtained after coating with a thin layer of gold with a Leitz (Model AMR 1000) SEM microscope.

\section{RESULTS AND DISCUSSION}

\section{Water content}

Water contents of polymer films treated with different plasma powers were determined (Table I). The untreated polymer was very hydrophobic, as are all PHBV, and did not absorb any water in the first $24 \mathrm{~h}$ and only $8.2 \%$ after $72 \mathrm{~h}$ of immersion. All the treated films absorbed more water than the untreated film, and the absorbance increased with the total power applied. The film with the highest water absorbing capability $(60.2 \%)$ was the one treated with the most oxygen plasma $(100 \mathrm{~W} \times 20 \mathrm{~min})$. These results confirm the expectation that the film treated with the highest level of oxygen plasma would be the most hydrophilic. The cause for high water absorption with this specific treatment mode could be (a) very high surface hydrophilicity and (b) degradation of the sample during treatment. We believe both these phenomena are valid because the contact angle of this sample could not be determined due to rapid absorption of water by the material.

\section{Water contact angle}

It is known that PHBs and their copolymers are quite hydrophobic polyesters, with the only polar functionality residing in the ester groups. The water content results reported in the previous section confirm this hydrophobicity. PHBV20 (HV content of $20 \%$ ) was reported to have a water contact angle of $\sim 68^{\circ}$, which decreased to $66^{\circ}$ on hydrolytic degradation. ${ }^{13}$ Ammonia gas plasma treatment of polyhydroxyoctanoate) led to a water contact angle decrease of $20-30^{\circ}$ from a very high value of $95^{\circ}$ as a result of stable incorporation of nitrogen in the structure. ${ }^{14}$ Following treatment 
TABLE II

Properties of the PHBV8 Samples after Treatment with Oxygen Plasma

\begin{tabular}{|c|c|c|c|c|c|c|}
\hline \multirow[b]{2}{*}{$\begin{array}{l}\text { Sample treatment type: } \\
\text { power }(\mathrm{W}) / \text { time }(\mathrm{min})\end{array}$} & \multirow[b]{2}{*}{$\begin{array}{c}\text { Total power } \\
\text { applied } \\
\text { (Watt } \times \text { min) }\end{array}$} & \multirow[b]{2}{*}{$\begin{array}{l}\text { Contact } \\
\text { angle } \\
\text { (degrees) }\end{array}$} & \multicolumn{3}{|c|}{$\mathrm{C}_{\mathrm{ls}}{ }^{\mathrm{a}}$} & \multirow[b]{2}{*}{$\begin{array}{c}\mathrm{O}_{1 \mathrm{~s}} \\
\text { Binding } \\
\text { energy, } \\
532.2 \mathrm{eV}\end{array}$} \\
\hline & & & $\begin{array}{l}-\mathrm{C}-\mathrm{H} \\
\text { Binding } \\
\text { energy, } \\
285.0 \mathrm{eV}\end{array}$ & $\begin{array}{l}-\mathrm{C}-\mathrm{O} \\
\text { Binding } \\
\text { energy, } \\
286.5 \mathrm{eV}\end{array}$ & $\begin{array}{l}-\mathrm{C}=\mathrm{O} \\
\text { Binding } \\
\text { energy, } \\
289.1 \mathrm{eV}\end{array}$ & \\
\hline Untreated & 0 & $68.3 \pm 7.8$ & $0.43(0.43)^{\mathrm{b}}$ & $0.35(0.35)$ & $0.22(0.22)$ & $0.82(0.48)$ \\
\hline $50 / 10$ & 500 & $53.3 \pm 6.3$ & $0.42(0.42)$ & $0.35(0.35)$ & $0.23(0.23)$ & $0.89(0.52)$ \\
\hline $50 / 20$ & 1000 & $50.5 \pm 13.2$ & $0.41(0.41)$ & $0.35(0.35)$ & $0.24(0.24)$ & $0.90(0.52)$ \\
\hline $100 / 10$ & 1000 & $43.3 \pm 3.3$ & $0.41(0.41)$ & $0.35(0.35)$ & $0.24(0.24)$ & $0.95(0.55)$ \\
\hline $100 / 20$ & 2000 & $-^{\mathrm{c}}$ & $0.42(0.42)$ & $0.36(0.36)$ & $0.22(0.22)$ & $0.98(0.57)$ \\
\hline
\end{tabular}

${ }^{a}$ Determined by XPS.

${ }^{\mathrm{b}}$ Corrected atomic composition in parentheses.

${ }^{c}$ Could not be measured because of the high porosity created by the plasma treatment.

with plasma (oxygen, ammonia, ${ }^{15}$ etc.), other polymers are also known to have moved towards higher hydrophilicities as indicated by lower contact angles and surface energies. In the present study, the untreated polymer had a significantly high contact angle $\left(68.3 \pm 7.8^{\circ}\right)$ that was substantially reduced (43.3 $\left.\pm 3.3^{\circ}\right)$ following oxygen plasma treatment $(100 \mathrm{~W}$ for $10 \mathrm{~min}$ ), as shown in Table II and Figure 1(a). It was also observed that the decrease in the contact angle was directly related with the extent of treatment

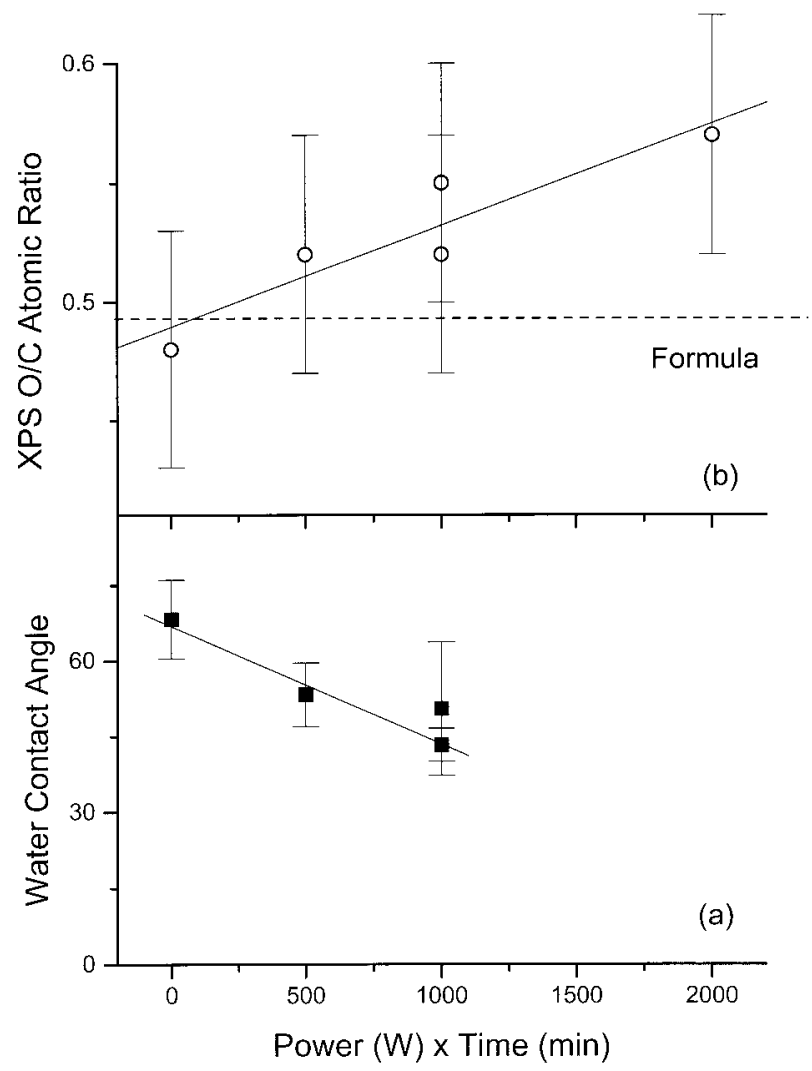

Figure 1 Variation of (a) water contact angle and (b) O/C atomic ratio (by XPS) of the oxygen plasma-treated PHBV8 films with the applied plasma power and duration. (power $\times$ duration; i.e., no significant difference was observed between $50 \mathrm{~W} \times 20 \mathrm{~min}$ and $100 \mathrm{~W} \times 10 \mathrm{~min}$ treatments), indicating that it is possible to modify surface hydrophilicity on demand. This observation is very important because it has been reported that cell adhesion on polymers is controlled by the surface energy. For example, a study of adherence of fibroblasts, endothelial cells, and L cells on polymer surfaces indicates that $70^{\circ}$ is optimum for adherence and that at higher or lower contact angles, adherence decreases sharply. ${ }^{16}$ Also, it was reported that fibroblast spreading on polymer surfaces showed a sudden increase at a surface energy of $40 \mathrm{erg} / \mathrm{cm}^{2}$ and further increases in the surface energy did not result in higher spreading. Thus, this technique becomes an important tool for tissue engineering applications, where surface chemistry is of utmost importance for cell loading, viability, and functionality. The porosity of the polymer films, however, increased on oxygen plasma treatment, and it was not possible to measure the contact angle of the $100 \mathrm{~W} \times 20 \mathrm{~min}$ sample because of the rapid transference of the water across the membrane. This result indicates that an excess of treatment not only leads to surface modification but could actually result in damage to the surface. Thus, plasma treatment needs to be applied carefully so as not to extensively modify and damage the surface.

\section{X-ray photoelectron spectroscopy}

The wide XPS spectra of the various films are shown in Figure 2. In addition to the strong $\mathrm{O}_{1 \mathrm{~s}}$ and $\mathrm{C}_{1 \mathrm{~s}}$ peaks, $\mathrm{N}_{1 \mathrm{~s}}$ peaks are observed in plasma-treated films. The $\mathrm{N}_{1 \mathrm{~s}}$ peaks are probably due to a small leak, residual $\mathrm{N}_{2}$ in the plasma chamber, or interaction with $\mathrm{N}_{2}$ in the air on opening of the chamber. $C_{1 s}$ peaks exhibit multiplet structure and are curve-fitted to (i) carbon bonded to hydrogen, (ii) etheric, and (ii) esteric components, as shown in Figure 2 and Table II. ${ }^{17}$ The $\mathrm{O}_{1 \mathrm{~s}}$ peaks are broad and become broader after plasma 


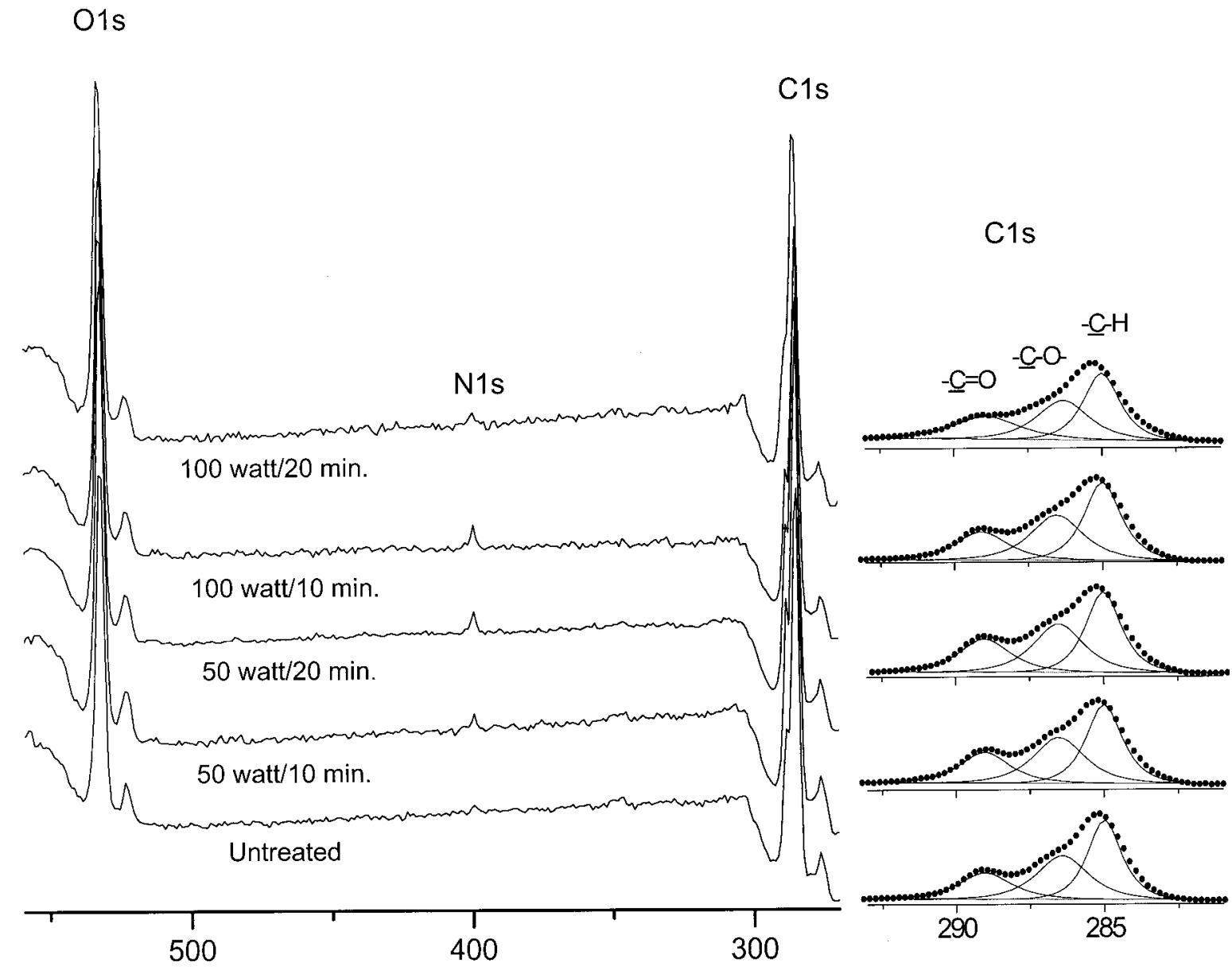

Figure 2 XPS spectra (wide) and the detailed C1s region (inset) following oxygen plasma treatment of PHBV8 films using different power and durations.

treatment. The $\mathrm{O} / \mathrm{C}$ atomic ratio derived from XPS measurements (0.48) matches exactly the expected ratio from the chemical formula (0.49) but increases up to 0.57 as a function of the plasma power and duration, as shown in Figure 1(b). To this end it is necessary to note that the changes in the $\mathrm{O} / \mathrm{C}$ atomic ratio are indistinguishable (within the experimental uncertainty) for the $50 \mathrm{~W} \times 20 \mathrm{~min}$ and $100 \mathrm{~W} \times 10 \mathrm{~min}$ treatments, which is similar to our water contact angle results.

The XPS sampling depth was $\sim 5 \mathrm{~nm}$. The atomic compositions involve both surface and subsurface layers and, in general, a direct comparison with water contact angle measurements is not expected. ${ }^{18,19}$ However, the decrease of the water contact angle as a function of plasma treatment surprisingly correlates directly with the $\mathrm{O} / \mathrm{C}$ atomic ratio increase, as depicted in Figure 1.

\section{Scanning electron microscopy}

Scanning electron microscopy of the PHBV8 films revealed a gradually increased surface roughness with increase in the total power applied (Figure 3). A sim- ilar observation was reported following argon treatment of poly(phenylene vinylene), where the uniformly smooth-surfaced pristine films became granular and rougher. ${ }^{20}$

\section{CONCLUSIONS}

In this study we showed, by changes in water absorbing capacity and water contact angle and by XPS and SEM investigations, that the surface properties of PHBV films containing $8 \%$ HV could be controllably modified by varying the power and the duration of the oxygen rf-plasma application. Our results showed that there was direct correlation between the gradual increase in the concentration of oxygen-containing groups on the membrane surface and increases in total power applied. This effect was manifest in the properties of the material as an increase in hydrophilicity.

It is known that plasma treatment modifies only the surface of treated samples. In this study, all the samples showed some wettability even before treatment, and after treatment they revealed low but consistent water absorptions. Only the samples treated with 100 $\mathrm{W} \times 20$ min plasma application seemed to absorb a 

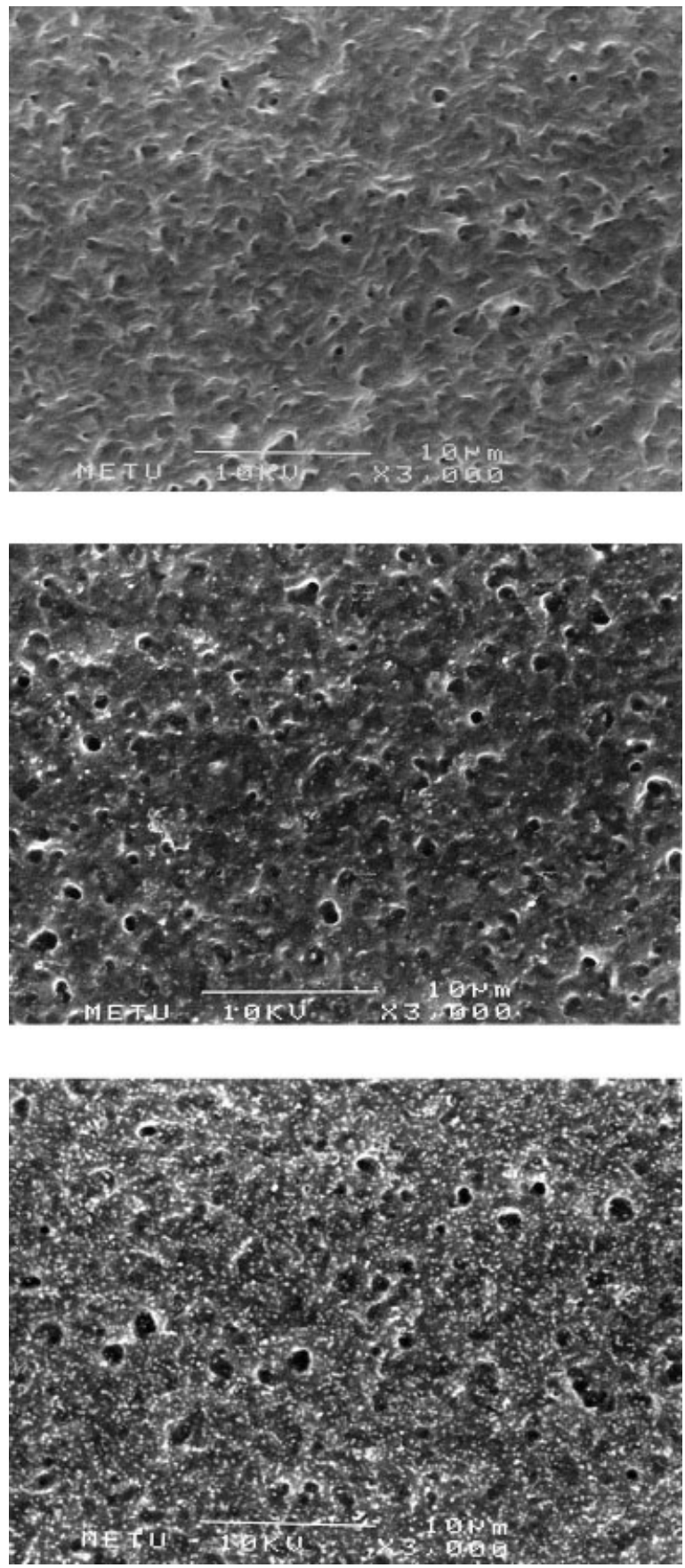

Figure 3 A composite SEM of untreated and oxygen plasma-treated PHBV8 films: (a) untreated; (b) treated with $50 \mathrm{~W}$ for $10 \mathrm{~min}$; (c) treated with $100 \mathrm{~W}$ for $20 \mathrm{~min}$. significant amount of water. This result was possibly due to very high surface hydrophilicity and degradation of sample during this treatment.

Hence, plasma modification of PHBV surfaces could help modify surface topography and tailor-make surface chemistry for tissue engineering applications in which surface properties are critical for cell adhesion and growth.

We acknowledge the METU AFP and TÜBITAK NATO grants for A. Tezcaner, and the State Planning Organization of Turkey for the chemicals.

\section{References}

1. Hasirci, V. In: Wise, D.L., Ed. Biomaterials and Bioengineering Handbook; Marcel Dekker: New York, 2000; pp. 141-155.

2. Rivard, C.H.; Chaput, C.J.; DesRosiers, E.A.; Yahia, L.H.; Selmani, A. J Appl Biomater 1995, 6, 65-68.

3. Sendil, D.; Gursel, I.; Wise, D.L.; Hasirci, V. J Controlled Release 1999, 59, 207-217.

4. Yagmurlu, M.F.; Korkusuz, F.; Gursel, I.; Korkusuz, P.; Ors, U.; Hasirci, V. J Biomed Mater Res 1999, 46, 494-503

5. van der Giessen, W.J.; Lincoff, A.M.; Schwartz, R.S.; van Beusekom, H.M.; Serruys, D.R.; Holmes, S.G.; Ellis, E.J. Topol. Circulation 1996, 94(7), 1690-1697.

6. Lee, M.Y.; Park, W.H.; Lenz, R.W. Polymer 2000, 41(5),17031709.

7. Pouton, C.W.; Akhtar, S. Adv Drug Delivery Rev 1996, 18(2), 133-162.

8. Nakamura, S.; Doi, Y.; Scandola, M. Macromolecules 1992, 25(17), 4235-4240.

9. Pool, R.G. Science. 1989, 245, 1187-1189.

10. Poirier, Y.; Somerville, C.; Schechtman, L.A.; Satkowski, M.M.; Noda, I. Int J Biol Macromol 1995, 17, 7-12.

11. Ertel, S.I.; Ratner, B.D.; Horbett, T.A. J Biomed Mater Res 1990, 24,1637-1659.

12. Hasirci, N. J Appl Polym Sci 1987, 34, 2457-2468.

13. Yasin, M.; Holland, S.J.; Jolly, A.M.; Tighe, B.J. Biomaterials 1989, 10, 400-412.

14. Williams, S.F.; Martin, D.P.; Horowitz, D.M.; Peoples, O.P. Int J Biol Macromol 1999, 25, 111-121.

15. Mason, M.; Vercruysse, K.P.; Kirker, K.R.; Frisch, R.; Marecak, D.M.; Prestwich, G.D.; Pitt, W.G. Biomaterials 2000, 21, 31-36.

16. Saltzman, W.M. In: Principles of Tissue Engineering; Lanza, R.P.; Langer, R.; Chick, W.L., Eds.; R.G. Landes Company: Austin, TX, 1996; pp. 225-246.

17. Beamson, G.; Briggs, D. High Resolution XPS of Organic Polymers; Wiley: New York, 1992

18. Süzer, S.; Argun, A.; Vatansever, O.; Aral, O. J Appl Polym Sci 1999, 74, 1846-1850.

19. Occhiello, E.; Mora, M.; Morini, G.; Garbassi, F.; Humphrey, P. J Appl Polym Sci 1991, 42, 551-559.

20. Nguyen, T.P.; Lahman, A.; Jonnard, P. J Adhesion 1998, 66, 303-317. 